\title{
Pengembangan Media Pembelajaran Bahasa Inggris Untuk Mahasiswa Pendidikan Sains
}

\author{
Musahrain $^{1, *}$, Ruly Morganna ${ }^{2}$, Hermansyah $^{1}$, Nurhairunnisah $^{1}$ \\ ${ }^{1}$ Universitas Samawa \\ ${ }^{2}$ Institut Agama Islam Negeri (IAIN) Curup \\ *musahrainbima@gmail.com
}

Artikel Info

Tanggal Publikasi

2019-12-30

\section{Kata Kunci}

Aplikasi Pembelajaran

Media Pembelajaran

Bahasa Inggris

Pendidikan Sains

\begin{abstract}
Abstrak
Penelitian ini bertujuan untuk mengembangkan media pembelajaran bahasa Inggris untuk calon guru Pendidikan sains. Media yang dikembangkan dapat dijalankan di laptop, computer dan smartphone. Materi yang disajikan dalam media pembelajaran ini berupa materi pembelajaran sain yang disajikan dalam Bahasa inggris. Metode yamg digunanakan dalam penelitian ini adalah metode penelitian pengembagan dengan megadopsi model penelitan 4-D. teknik pengumpulan data dilakuan dengan cara observasi, wawancara dan angket. Teknik analisis data menggunakan deskriptif kuantitatif. Hasil dari evaluasi ahli media dan ahli materi media yang dikembangakna berada pada kategori sangat bait dengan rata- rata skor yang di peroleh 4 . Sementara hasil uji coba diperoleh skor rata-rata 3.5 artinya media yang dikembangankan sangat baik dan layak untuk digunakan.
\end{abstract}

\section{PENDAHULUAN}

Dalam dimensi komunikasi internasional, bahasa Inggris dikenal dengan istilah bahasa lingua franca dunia (Fang, 2017; Idris, 2020; Kirkpatrick, 2018; Kusumaningputri \& Widodo, 2018; J. Liu \& Fang, 2017; Mauranen, 2018; Morganna, Sumardi, \& Tarjana, 2018, 2020). Status bahasa Inggris sebagai bahasa lingua franca dunia ini semakin absah karena dunia kerja, untuk ruang lingkup antar negara, menggunakan bahasa Inggris sebagai media komunikasi (Lauder, 2008). Kondisi seperti ini akhirnya menggiring para akademisi dan pendidik yang berorientasi pada dunia pendidikan bahasa Inggris untuk mengonsepkan dan mengembangkan sistem pembelajaran bahasa Inggris untuk tujuan khusus (English for specific purpose) atau biasa juga disingkat dengan ESP (Ai, Kostogriz, Wen, \& Wang, 2018; Okada, 2015). Laiknya pembelajaran pada umumnya, pembelajaran ESP juga menuntut adanya media yang relevan yang sesuai dengan kebutuhan pelajarnya, yang pada umumnya adalah pelajar dewasa, di mana secara konsep mental, mereka sudah memetakan peran bahasa Inggris terkait bidang profesi yang sedang mereka pelajari atau tekuni (Nguyen, Haworth, \& Hansen, 2019; Xu, Chan, \& Yilin, 2018).

Di era revolusi 4.0, pembelajaran bahasa Inggris sudah mulai bertransformasi dengan melibatkan teknologi sebagai pendukung pembelajaran (Barclay, Donalds, \& Osei-Bryson, 2018; Hernández-Lara \& Serradell-López, 2018; Martin, Wang, \& Sadaf, 2018; Santos \& Cechinel, 2019; Thongsri, Shen, \& Bao, 2019; Wei, Peng, \& Chou, 2015). Banyak dari para akdemisi dan pendidik di bidang pendidikan bahasa Inggris yang mengorientasikan kajian penelitian mereka di area mobile assisted language learning (MALL) karena mobile phone atau telefon genggam yang memiliki akses internet sudah dimiliki oleh hampir semua orang dari semua kalangan termasuk kalangan pelajar (Hsu, 2013). Penelitian-penelitian terdahulu yang dikerangkai teori MALL sudah dilakukan oleh berbagai peneliti dan meliputi berbagai aspek dalam konteks pendidikan bahasa Inggris. Aspek-aspek itu misalnya adalah penggunaan MALL dalam proses pembelajaran (Liu \& Chen, 2015), pengguaan MALL dalam hal evaluasi belajar seperti untuk memberi umpan balik hasil belajar bahasa Inggris kepada peserta didik (Ghorbani \& Ebadi, 2019), penggunaan MALL terkait perannya dalam menyokong perkembangan kemampuan 
metakognitif peserta didik dalam belajar bahasa Inggris (García Botero, Questier, \& Zhu, 2019), dan banyak lagi termasuk peran MALL dalam memenuhi kebutuha media pembelajaran bahasa Inggris (Hwang \& Fu, 2019; Qian, Owen, \& Bax, 2018; Zhang \& Pérez-Paredes, 2019).

Keberlanjutan penelitian terkait peran MALL dalam hal media pembelajaran bahasa Inggris sangat penting untuk dilakukan karena media dan sumber belajar merupakan dua hal yang paling penting dalam menunjang keberhasil belajar peserta didik. Keduanya diibarkan dua sisi mata pisau yang saling mendukung antara satu sama lain. Bagaiamana tidak, media merupakan alat pendukung yang mempermulus jalannya pesan yang disampaikan oleh pendidik kepada peserta didik (Anitah, 2012), serta dapat membantu siswa dalam meningkatkan pemahaman materi ajar (Puspitaningrum, 2019). Sementara sumber belajar adalah pusat pemerolehan pesan yang akan disampaikan. Penggunaan media pembelajaran juga akan mampu mengatasi berbagai keterbatasan baik itu keterbatasan ruang, waktu, tenaga, serta daya indra (Daryanto, 2010), disamping itu media dapat mendorong keikutsertaan peserta didik dalam memahami konsep ilmu yang diajarkan (Yin C, 2013).

Pengembangan media pembelajaran Bahasa inggris di era revolusi industri 4.0 ini menghasilkan berbagai jenis media pembelajaran salah satunya adalah media aplikasi pembelajaran berbasis smartphone atau android. Pengembangan media aplikasi pembelajaran bahasa Inggris seperti ini penting untuk terus dilakukan karena banyak aplikasi-aplikasi pembelajaran yang ada di smartphone atau android belum terdesain khusus untuk pelajar Bahasa Inggris (Chik, 2014). Sementara, media aplikasi berbasis smartphone atau adroid sangat berpotensi untuk menyokong perkembangan kompetensi bahasa Inggris peserta didik karena media seperti ini memberikan keleluasaan terhadap pengguna tanpa dibatasi oleh ruang dan waktu (Qian et al., 2018). Penggunaan media pembelajaran Bahasa inggris seperti ini juga memberikan kemudahan bagi pengguna dalam mencari referensi dan sumber lain diluar dari pada aplikai yang dikembangkan.

Pengembangan media aplikasi pembelajaran berbasis android ini memang sudah bukan lagi menjadi hal baru dalam dunia Pendidikan. Pengembangan media seperti ini telah banyak yang dilakukan oleh peneliti-peneliti sebelumnya khususnya di bidang Bahasa Inggris, beberapa di antaranya, seperti yang dilakukan oleh Liu (2017); Muslaini, Kristina, dan Sutomo (2019); Shandu (2018); dan Wariyant (2019). Penelitian yang mereka lakukan merujuk pada kerangka bahasa Inggris umum (General English) yang diorientasikan pada ranah-ranah seperti, English vocabulary, English for adult learners, English skills dan lain sebagainnya. Namun, masih sangat terbatas penelitian yang mengembangkan media dan sumber belajar berbasis English Specific Purposes (ESP). Dalam konteks pendidikan di perguruan tinggi, minimnya ketersedian media dan sumber belajar berbasis ESP ini menjadi salah satu kendala mahasiswa dalam mempelajari dan memahami materi bahasa Inggris yang sesauai dengan bidang mereka, sehingga keadaan ini berdampak pada tingkat pemahaman dan kemampuan mahasiswa dalam memahami dan menguasai materi-materi berbahasa Inggris.

Materi dan media yang digunakan seharusnya sejalan dengan jurasan atau program studi yang diampu oleh mahasiswa sehingga dapat diaplikasikan secara langsung dalam proses belajar mengajar. Namun pada kenyataannya media dan sumber belajar yang digunakan dalam proses perkuliahan selama ini cenderung bertolak belakang dengan bidang studi atau jurusan yang mereka tempuh sehingga tidak ada korelasi atau hubungan antara materi-materi yang diajarkan dalam bahasa Inggris dengan jurusan yang diambil baik itu biologi, maupun fisika, dan ini berdampak pada tidak tercapain belajar (learning outcomes) yang diharapkan.

Pembelajaran Bahasa inggris untuk Pendidikan tinggi sudah seharusnya tidak lagi diajarkan secara penuh dalam kerangka General English saja, melainkan mereka sepatutnya diarahkan atau disajikan dengan materi-materi yang berhubungan dengan bidang studi mereka atau yang biasa di kenal dengan English specific purposes (ESP). ESP adalah suatu pendekatan pembelajatran bahasa Inggris dengan tujuan khusus. ESP mempunyai tujuan dan pendekatan yang sangat berbeda dengan General 
English (GE). Robinson (1990) mengungkapkan bahwa ESP umumnya digunakan untuk belajar mengajar bahasa asing yang sesuai dengan tujuan dan tanpa ada keraguan. Lebih lanjut pembelajaran ESP adalah dimana silabus dan materi yang digunakan harus disusun berdasarkan hasil analisis sebelumnya dan sesuai dengan kebutuhan peserta didik (Donough, 1984).

ESP adalah suatu pendekatan yang dilakukan dalam proses belajar mengajar dengan melihat kebutuhan peserta didik berdasarkan hasil analisis sebelum nya dan menjadi acuan dalam penyusunan silabus dan materi sehingga tidak ada sangsi dalam penggunaannya. Tujuan dari pada pembelajaran ESP ini adalah agar peserta didik mampu memahami dan menggunakan bahasa Inggris sesuai dengan bidang mereka. Dengan demikian, mereka akan mudah memperoleh informasi, ilmu dan pengetahuan yang disajikan dalam bahasa Inggris.

Berdasarkan berbagai permasalahan dan ulasan terkait pentingnya pengembangan media aplikasi berbasis android seperti yang digambarkan di atas, maka peneliti melakukan pengembangan media dan sumber belajar bahasa Inggris bagi para mahasiswa FKIP UNSA dengan harapan akan menjadi sebuah solusi atas keterbatasan media dan sumber belajar bahasa Inggris untuk sains. Penelitian ini diharapkan dapat membantu mereka dalam mempelajari dan memahami bahasa Inggris yang sesuai dengan bidang ilmu yang mereka ampu. Pengembangan ini tentunya disesuaikan dengan lingkungan dan latar belakang mahasiswa (Arif Sadiman, 2009). Di samping itu pemilihan media yang digunakan dalam pengembangan ini telah disesuaikan dengan keadan ekonomi mahasiswa, kemudahan dalam mengakses, kepraktisan dan flexibilitasnya (Rivai, 2007).

\section{METODE PENELITIAN}

Jenis penelitian ini adalah penelitian pengembangan atau yang biasa disebut dengan Research and Development $(\mathrm{R} \& \mathrm{D})$. Model pengembangan yang digunakan dalam penelitian ini adalah model 4-D dengan 4 tahapan utama yaitu, Define, Design. Development, and Dessimination (Thiagarajan, 1974) yang dimodifikasi, dalam artian bahwa peneliti tidak menggunakan ke-empat tahapan tersebut secara penuh. Peneliti melakukan modifikasi pada tahap akhir yaitu pada tahap desiminasi. subjek penelitai berjumlah 15 orang yang di ambil secara acak.

Instrumen yang digunakan dalam penelitian ini berupa angket yang diadaptasi dari skala likert dengan menggunakan skala empat (sangat setuju, setuju, kurang setuju dan tidak setuju), serta lembar validasi. Angket didesain dengan menggunakan format checklist dengan tujuan untuk memperoleh data responden, sementara angket validasi digunakan untuk mengetahui tingkat kelayakan materi dan media.

Data yang diperoleh baik dari responden maupun tim validasi selanjutnya akan dianalisis dengan menggunkan tekhnik deskriptif kuantitatif dengan menggunkan formula $P=\frac{\text { perolehamn skor }}{\text { skor maksimal }} \times 100 \%$

\section{HASIL DAN PEMBAHASAN}

\section{Pengumpulan data}

Pengumpulan data merupakan sebuah proses yang dilakukan untuk memperoleh berbagai material yang dibutuhkan baik untuk kebutuhan media maupun materi. Pengumpulan material yang digunakan dalam media dan sumber belajar ini adalah dengan mengumpulkan gambar-gambar, icon, dan lainnya yang akan membantu mengilustrasikan materi yang disajikan dan berbagai sumber lain baik dari buku-buku, jurnal, modul, dan lainnya yang berhubungan dengan materi sains.

\section{Analisis}

Pada tahap ini peneliti melakukan analisa kemampuan awal mahasiswa, ketersediaan sarana dan prasana baik berupa media maupun sumber belajar. Pada fase ini peneliti melakukan beberapa langkah 
untuk mendapatkan data yang dibutuhkan. Problem analysys, dengan tujuan untuk memperoleh atau mengetahui masalah, learner analysis, untuk mengetahui karakteristik dan learning experiences, dan media. Task analysis digunakan untuk mengetahui pemahaman dan kemampuan awal mahasiswa. Kegiatan ini dilakukan dengan cara pemberian kuis sebagai pretest. Concept analysis digukan untuk menganalisis konsep dan spesifukasi materi serta mentukan tujuan pemebelajaran.

\section{Desain}

Tahap ini bertujuan untuk merancang prototype media yang akan dikembangkan dengan melakukan bebera tahapan seperti: Pertama, Penyususnsn Kriteria Materi. Pada tahap atau fase ini peneliti menyusun kriteria materi yang digunakan sebagai acuan dan disesuaika dengan tujuan yang telah ditetapkan. Kudua, Pemilihan Media yang bertujuan untuk menentukan media yang akan digunakan sesuai dengan karakteristik, latar belakang dan ekonomi mahasiswa serta kemudahan dalam mengakses dan flexibilitasnya. Ketiga, Penentuan Format Media yang akan dikembangkan, dan terakhir adalah menyusun Story Board dengan tujuan untuk mempemudah proses perancanagan media yang dikembangkan.

\section{Pengembangan}

Pada tahap ini peneliti mulai melakukan pengembangan media belajar yang sesuai dengan apa story board draft yang telah dibuat sebelumnya dan disesuaiakan dengan masukan dan komentar dari para ahli sehingga menghasilkan sebuah media yang siap diujicobakan dan menghasilkan produk media final.

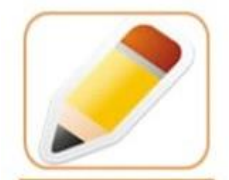

KOMPETENSI
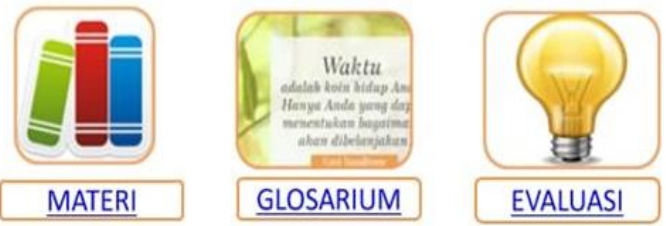

Gambar 1. Menu Utama

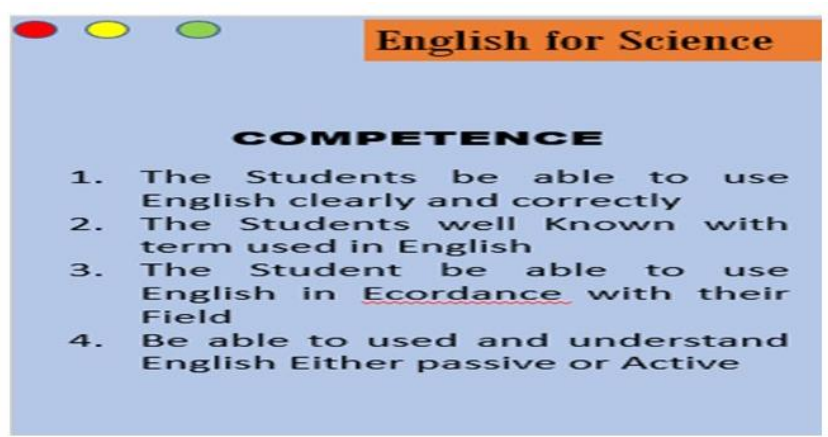

Gambar 2. Menu Kompetensi

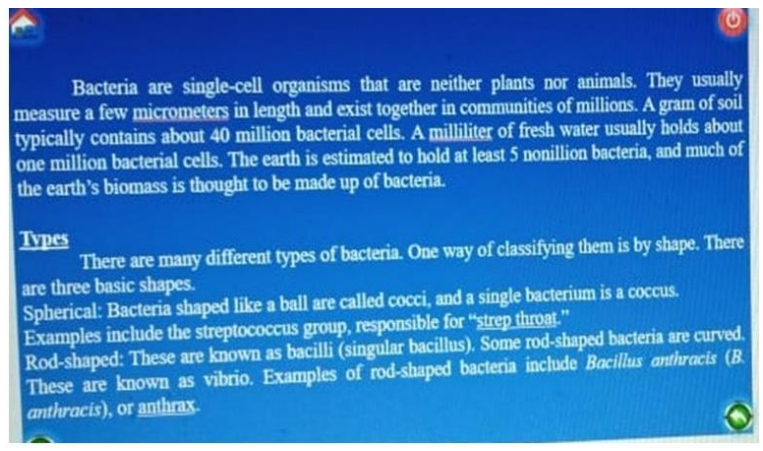

Gambar 3. Menu Materi

Produk yang final yang dihasilkan dari pengembangan ini adalah berupa media pembelajaran dengan luaran filenya berupa htm15 yang dapat dijalankan di komputer dan laptop serta APK yang dijalankan dengan menggunakan smartphone. Media ini memuat materi pembelajaran bahasa Inggris untuk sains, yaitu fisika dan biologi yang disajikan dalam beberapa menu yiatu, menu kompetensi yang memuat capaian pembelajaran, menu materi memuat materi-materi sains yang disajikan dalam bentuk Bahasa Inggris, menu glosarium menyajikan kata-kata sulit atau istilah-istilah sains dalam Bahasa inggris, dan menu kuis memuat serangkaian soal-soal sebagai bahan Latihan atau evaluasi yang langsung terhubung ke email peneliti baik dari ahli materi maupun ahli media diperoleh hasil yang sangat baik. Dalam artian bahwa media yang dikembangkan sangat baik dan layak untuk digunakan. Untuk lebih jelasnya, hasil dari kedua validasi tersebut disajikan dalam table berikut ini. 
Tabel 1. Hasil validasi ahli materi

\begin{tabular}{ccc}
\hline Aspek & Rata-rata skor & Kategori \\
\hline Kelayakan isi & 4 & Sangat baik \\
Kelayakan penyajian & 3 & Baik \\
Kelayakan Bahasa & 4 & Sangat baik \\
\hline
\end{tabular}

Berdasarkan hasil penilain ahli materi dari ketiga aspek yang dinilai baik dari segi aspek kelayakan isi, kelayakan penyajian maupun aspek kelayakan bahasa diperoleh nilaia rata-rata empat dengan kategori sangat baik. Itu artinya bahwa muatan materi yang terdapat dalam media bisa dan layak untuk digunkan. Sementara hasil penilaan dari ahli media dari 4 aspek penilaian dapat dilihat pada Tabel 2.

Tabel 2. Penilaian Ahli Media

\begin{tabular}{lcc}
\hline \multicolumn{1}{c}{ Aspek } & Rata-rata skor & Kategori \\
\hline Kompetensi media & 3 & Baik \\
Halaman pembuka & 3 & Baik \\
Halaman kompetensi & 4 & Sangat baik \\
Halaman materi & 4 & Sangat baik \\
Halaman ujian & 4 & Sangat baik \\
Profil pengembang & 4 & Sangat Baik \\
\hline
\end{tabular}

Dari Tabel 2 dapat dilihat dengan jelas bahwa media yang dikembangkan berada pada kategori sangat baik dengan rata-rata skor yang diperoleh 4 .

\section{Uji coba produk}

Pada fase ini peneliti melakukan uji coba produk dengan tujuan untuk mengetahui tingkat kelayakan produk yang dikembangkan. Berdasarkan hasil uji coba yang dilakukan dengan melibatkan 10 orang responden (mahasiswa) yang dipilih secara acak, diperoleh hasil dengan nilai rata-rata 3,5. Itu artinya bahwa media yang dikembangankan berada pada kategori baik dan layak untuk digunakan. Hasil uji coba produk ini sejalan dengan uji coba yang dilakukan oleh (mauliana, 2019).

Hasil penelitian ini sejalan dengan penelitian yang dilakukan oleh (Ramlah Basyir, 2016) yang menyatakan bahwa produk yang dikembangkan layak untuk digunakan. Perbedaan penelitian ini dengan penelitian yang dilakukan oleh Basyir dkk (2016) adalah pada model pengembangan, materi dan aplikasi yang digunakan untuk mengembangkan produk media alternatif yang dapat digunakan untuk menunjang pembelajaran English Specifik Purposes (ESP) khusunya pada bidang sains. Berdasarkan hasil validasi, uji kelompok kecil, dan uji coba terbatas di peroleh bahwa media yang dikembangkan layak untuk digunakan dengan predikat sangat baik. Keunggulan dari media ini adalah mahasiswa dapat menggunakanakannya kapan saja dan dapat mendorong pembelajajaran mandiri serta dapat digunakan secara berulang.

\section{KESIMPULAN}

Berdasarkan hasil penelitian, dapat disimpulkan bahwa media pembelajaran yang dikembangkan dapat dijadikan sebagai media alternatif yang dapat digunakan untuk menunjang pembelajaran English Specifik Purposes (ESP) khusunya pada bidang sains. Berdasarkan hasil validasi, uji kelompok kecil, dan uji coba terbatas di peroleh bahwa media yang dikembangkan layak untuk digunakan dengan predikat sangat baik. Keunggulan dari media ini adalah mahasiswa dapat menggunakanakannya kapan saja dan dapat mendorong pembelajajaran mandiri serta dapat digunakan secara berulang. 


\section{Daftar Pustaka}

Ai, B., Kostogriz, A., Wen, D., \& Wang, L. (2018). Student presentations as a means of teaching and learning English for Specific Purposes: an action research study. Teaching in Higher Education,1-15. https://doi.org/10.1080/13562517.2018.1557136

Anitah, S. (2012). Media Pembelajaran. Surakarta: UNS Press.

Arif Sadiman, R. R. (2009). Arif Sadiman, R. R. (2009). Media Pendidikan: Pengertian, Pengembangan dan Pemanfaatanya. Jakarta: Rajawali Press. Jakarta: Rajawali Press.

Barclay, C., Donalds, C., \& Osei-Bryson, K. M. (2018). Investigating critical success factors in online learning environments in higher education systems in the Caribbean*. Information Technology for Development, 24(3), 582-611. https://doi.org/10.1080/02681102.2018.1476831

Chik, A. (2014). English Language Teaching Apps: Positioning Parents and Young Learners. Changing English: Studies in Culture and Education, 21(3), 252-260. https://doi.org/10.1080/1358684X.2014.929285

Daryanto. (2010). Media Pembelajaran. Yogyakarta: Grava Media.

Donough, J. M. (1984). ESP in Perspective a Praktical Guide. London: Collin ELT.

Fang, F. G. (2017). World Englishes or English as a Lingua Franca: Where does English in China stand? English Today, 33(1), 19-24. https://doi.org/10.1017/S0266078415000668

García Botero, G., Questier, F., \& Zhu, C. (2019). Self-directed language learning in a mobile-assisted, out-of-class context: do students walk the talk? Computer Assisted Language Learning, 32(1-2), 7197. https://doi.org/10.1080/09588221.2018.1485707

Ghorbani, N., \& Ebadi, S. (2019). Exploring learners' grammatical development in mobile assisted language learning. Cogent Education, 6(1). https://doi.org/10.1080/2331186X.2019.1704599

Hernández-Lara, A. B., \& Serradell-López, E. (2018). Student interactions in online discussion forums: their perception on learning with business simulation games. Behaviour and Information Technology, 37(4), 419-429. https://doi.org/10.1080/0144929X.2018.1441326

Hsu, L. (2013). English as a foreign language learners' perception of mobile assisted language learning: a cross-national study. Computer Assisted Language Learning, 26(3), 197-213.

Hwang, G. J., \& Fu, Q. K. (2019). Trends in the research design and application of mobile language learning: a review of 2007-2016 publications in selected SSCI journals. Interactive Learning Environments, 27(4), 567-581. https://doi.org/10.1080/10494820.2018.1486861

Idris, M. M. (2020). Assessing intercultural competence (IC) of state junior high school English teachers in Yogyakarta. Indonesian Journal of Applied Linguistics, 9(3), 628-636. https://doi.org/10.17509/ijal.v9i3.23213

Kirkpatrick, A. (2018). The development of English as a lingua franca in ASEAN. In J. Jenkins, W. Baker, \& M. Dewey (Eds.), The Routledge Handbook of English as a Lingua Franca (pp. 138-150). New York: Routlage.

Kusumaningputri, R., \& Widodo, H. P. (2018). Promoting Indonesian university students' critical intercultural awareness in tertiary EAL classrooms: The use of digital photograph-mediated intercultural tasks. System, 72, 49-61. https://doi.org/10.1016/j.system.2017.10.003

Lauder, A. (2008). The status and function of English in Indonesia: A review of key factors. Makara, Social Humaniora, 12(1), 9-20. 
Liu, J., \& Fang, F. (Gabriel). (2017). Perceptions, awareness and perceived effects of home culture on intercultural communication: Perspectives of university students in China. System, 67, 25-37. https://doi.org/10.1016/j.system.2017.04.003

Liu, P.-L., \& Chen, C.-J. (2015). Learning English through actions: a study of mobile-assisted language learning. Interactive Learning Environments, 23(2), 158-171. https://doi.org/10.1080/10494820.2014.959976

Liu, T.-Y. (2017). Developing an english mobile learning attitude scale for adult learner. Journal of Educational Technology Systes.

Martin, F., Wang, C., \& Sadaf, A. (2018). Student perception of helpfulness of facilitation strategies that enhance instructor presence, connectedness, engagement and learning in online courses. Internet and Higher Education, 37(March 2017), 52-65. https://doi.org/10.1016/j.iheduc.2018.01.003

Mauliana, A. d. (2019). Pengembangan Perangkat Pembelajaran Fisika dengan Pendekatan Neuroscience untuk meningkatkan pemahaman Konsep Siswa SMA. Jurnal Pendidikan MIPA, 59. 66.

Mauranen, A. (2018). Conceptualising ELF. In J. Jenkins, W. Baker, \& D. Martin (Eds.), The Routledge Handbook of English as a Lingua Franca (pp. 7-24). New York: Routlage.

Morganna, R., Sumardi, \& Tarjana, S. S. (2018). Immersion vs. construction: The portrayals of culture in Indonesian EFL learning paradigm. Journal of Language and Linguistic Studies, 14(2), 283-304. Retrieved from https://www.jlls.org/index.php/jlls/article/view/969/385

Morganna, R., Sumardi, \& Tarjana, S. S. (2020). Tertiary English students' attitudes towards intercultural language learning. Indonesian Journal of Applied Linguistics, 9(3), 657-665. https://doi.org/10.17509/ ijal.v9i3.23216

Muslaini, F., Kristina, D., \& Sutomo, N. (2019). A preliminary study of EFL reading android application development. International Online Journal of Education and Teaching (IOJET), 6(1), 151168.

Nguyen, B. H., Haworth, P., \& Hansen, S. (2019). Challenging ESP teacher beliefs about active learning in a Vietnamese university. Teacher Development, 23(3), 345-365. https://doi.org/10.1080/13664530.2019.1598481

Okada, Y. (2015). Contrasting identities: a language teacher' s practice in an English for Specific $\begin{array}{lllll}\text { Purposes classroom. } & \text { Classroom } & \text { Discourse, } & 6(1),\end{array}$ https://doi.org/10.1080/19463014.2014.961092Ai, B., Kostogriz, A., Wen, D., \& Wang, L. (2018). Student presentations as a means of teaching and learning English for Specific Purposes: an action research study. Teaching in Higher Education,1-15. https://doi.org/10.1080/13562517.2018.1557136

Qian, K., Owen, N., \& Bax, S. (2018). Researching mobile-assisted Chinese-character learning strategies among adult distance learners. Innovation in Language Learning and Teaching, 12(1), 56-71. https://doi.org/10.1080/17501229.2018.1418633

Ramlah Basyir, m. K. (2016). Rancang Bangun Aplikasi Android Media embelajaran Kosa Kata Bahasa Arab Bergambar dengan Menggunakan Model Pendekatan ADDIE. Jurnal Ilmiah EDUTIC-Jurnal Pendidikan dan Informatika.

Rivai, N. S. (2007). Teknologi Pengejaran. Bandung: Sinar Baru algesindo.

Robinson, P. (1990). English for Specific Purposes. Oxford: Paragon Press. Ltd. 
Santos, H. L. dos, \& Cechinel, C. (2019). The final year project supervision in online distance learning: assessing students and faculty perceptions about communication tools. Behaviour and Information Technology, 38(1), 65-84. https://doi.org/10.1080/0144929X.2018.1514423

Shandu, M. M. (2018). Developing a Mobile App for Learning English Vocabulary in an Open Distance Learning Context. International Review of Research in Open and Distributed Learning, 1-15.

Puspitaningrum, A.A., E. S. (2019). Pengembangan Media Pembelajaran Berbasis Android Pada Materi Routing Statis. Jurnal Ilmiah EDUTIC-Jurnal Pendidikan dan Teknologi.

Thiagarajan, S. S. (1974). Instructional Development for Training Teacher of Expectional Children. Minneapolish, Minneasota: University of Minneasota.Qian, K., Owen, N., \& Bax, S. (2018). Researching mobile-assisted Chinese-character learning strategies among adult distance learners. Innovation in Language Learning and Teaching, 12(1), 56-71. https://doi.org/10.1080/17501229.2018.1418633

Thongsri, N., Shen, L., \& Bao, Y. (2019). Investigating factors affecting learner's perception toward online learning: evidence from ClassStart application in Thailand. Behaviour and Information Technology, 38(12), 1243-1258. https://doi.org/10.1080/0144929X.2019.1581259

Wariyanti, S. L. (2019). Developing Android-Based English Learning Material. INTENSIVE JOURNAL, $62-72$.

Wei, H. C., Peng, H., \& Chou, C. (2015). Can more interactivity improve learning achievement in an online course? Effects of college students' perception and actual use of a course-management system on their learning achievement. Computers and Education, 83, 10-21. https://doi.org/10.1016/j.compedu.2014.12.013

Xu, X., Chan, F. M., \& Yilin, S. (2018). Personal learning environment: an experience with ESP teacher training. Interactive Learning $1-16$. https://doi.org/10.1080/10494820.2018.1552872

Yin C, S. Y.J. (2013). Developing and Implementation a Frame Work of Participatory Simulation for Mobile Learning Using Scaffolding. Educational Technology EO Society, 137-153.

Zhang, D., \& Pérez-Paredes, P. (2019). Chinese postgraduate EFL learners' self-directed use of mobile English learning resources. Computer Assisted Language Learning, 0(0), 1-26. https://doi.org/10.1080/09588221.2019.1662455 